\title{
О НОВОМ КОЭФФИЦИЕНТЕ ФОРМЫ, УЧИТЫВАЮЩЕМ РАЗМЕРЫ ПРЯМОУГОЛЬНЫХ ОБРАЗЦОВ ГОРНЫХ ПОРОД
}

\author{
И.Л. Паньков \\ Горный институт УрО РАН, г. Пермь
}

\begin{abstract}
Аннотация: Разработан новый коэффициент формы горных пород экспоненциального вида, учитывающий высоту, ширину и длину прямоугольных образцов горных пород. Проведено сопоставление расчетных данных с результатами экспериментальных исследований на сжатие прямоугольных образцов сильвинита, имеющих соотношение высоты к ширине - 1:1 и 2:1, а длины к ширине - 1:1, 2:1, 4:1 и 6:1. Приведены результаты исследования изменения теоретического коэффициента формы в зависимости от соотношения размеров прямоугольных образцов сильвинита, каменной соли, карналлита и ангидритдоломитовых пород.
\end{abstract}

Ключевые слова: горная порода, предел прочности, коэффициент формы, размер прямоугольных образцов

Безопасное ведение подземных горных работ при разработке месторождений полезных ископаемых подразумевает поддержание налегающей толщи пород целиками различного назначения. Большое влияние на несущую способность целика оказывает коэффициент формы, параметры уравнения которого определяются при испытаниях на сжатие образцов горных пород с различным отношением высоты $(h)$ и ширины $(b)$.

Зависимости, наиболее часто используемые в геомеханических расчетах для определения коэффициента формы горных пород, приведены в работе [1]. По виду уравнения зависимости подразделяются на прямые, гиперболические и логарифмические. В работе [2] предложено коэффициент формы записывать в виде экспоненциальной зависимости:

$$
K_{f}=e^{m \cdot\left(\frac{b}{h}-0,5\right)},
$$

где $m$ - экспериментально получаемый показатель, определяемый при испытании на сжатие образцов породы различной высоты и одинаковой ширины.

Несмотря на большое количество работ, посвященных коэффициенту формы горных пород, исследования, учитывающие влияние длины $(l)$ образцов (целиков) на их несущую способность практически отсутствуют. В этой связи в нормативных документах по ведению горных работ в расчетных формулах размеров целиков с учетом их длины используются достаточно упрощенные зависимости. Так, на рудниках Верхнекамского месторождения калийных солей, согласно действующим «Указаниям...» [3], влияние длины целиков на их агрегатную прочность производится с помощью коэффициента, учитывающего влияние прорезки ленточных междукамерных целиков по формулам:

$$
k_{c}=\left\{\begin{array}{rr}
1+0,125 \sqrt{l / b-1}, \text { при } & 1 \leq l / b<5 \\
1,25 & \text {, при } \\
l / b \geq 5 .
\end{array}\right.
$$

С целью разработки нового коэффициента формы, учитывающего соотношение трех основных размеров - высоты, длины и ширины поддерживающих целиков, проведен комплекс экспериментальных исследований на прямоугольных образцах сильвинита различной длины и высоты, результаты которых приведены в работе [4]. По результа- 
там экспериментов получены прочностные показатели, используемые для построения эмпирических зависимостей влияния длины образца на коэффициент формы. Установлено, что с увеличением длины образца коэффициент формы возрастает, при этом интенсивность роста коэффициента формы уменьшается с увеличением высоты и длины образца.

Для описания характера изменения коэффициента формы в зависимости от высоты, ширины и длины образцов проведено преобразование выражения (1) в уравнение следующего вида:

$$
K_{f}(h, b, l)=e^{m \cdot\left(\frac{b}{h}-0,5\right)} \cdot\left(\frac{s+1}{s+b / l}\right)^{p},
$$

где $s$ - задаваемый эмпирический параметр, имеющий положительную величину; $p-$ параметр, определяемый с помощью выражения:

$$
p=\frac{\ln \frac{2 \sigma_{\text {сж } 2}}{\sigma_{\text {сж } 2}+\sigma_{\text {сж1 }}}}{\ln (1+1 / s)},
$$

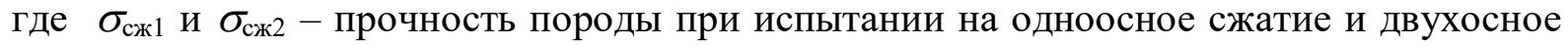
равнокомпонентное сжатие (схема испытаний приведена в работе [5]).

Расчетные кривые изменения коэффициента формы в зависимости от относительной длины образца $(l / b)$ приведены на рис. 1. Для сопоставления на рисунке показаны осредненные данные испытаний, полученные на образцах сильвинита различной длины и приведенные в работе [4]. Как видно, расчетные кривые качественно и количественно сопоставимы с данными экспериментальных исследований. Некоторые расхождения с результатами лабораторных исследований, по всей видимости, объясняются естественным разбросом экспериментальных данных.

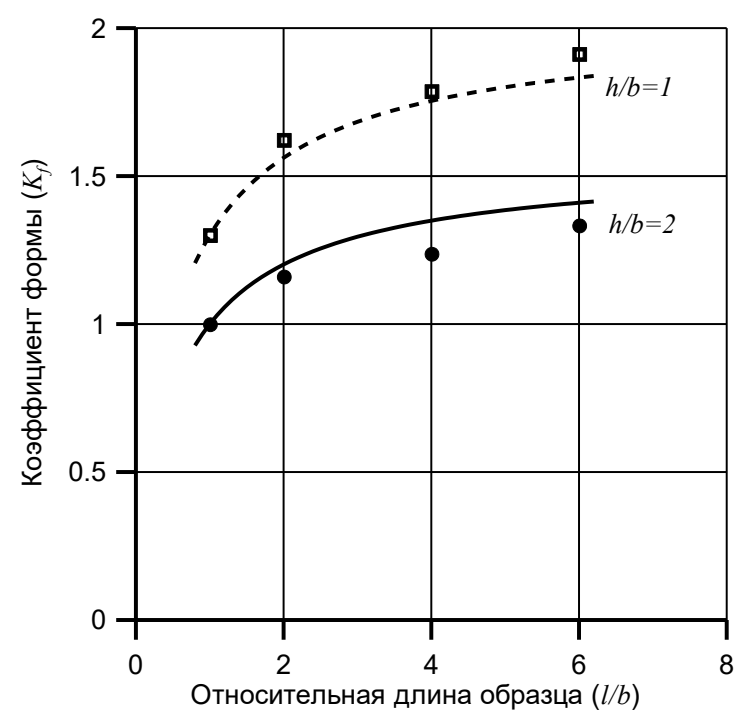

Рис. 1. Результаты сопоставительного анализа теоретического коэффициента формы с данными экспериментальных исследований

Формула (3) использовалась при изучении изменения теоретического коэффициента формы образцов продуктивных и вмещающих пород Гремячинского месторождения калийных солей в зависимости от отношения высоты к ширине и длины к ширине. С 
этой целью проведен анализ и оценка осредненных прочностных показателей сильвинита, каменной соли, карналлита и ангидрит-доломитовой породы. Результаты оценки прочностных показателей приведены в табл. 1.

Таблица 1

Оценочные прочностные показатели пород Гремячинского месторождения калийных солей

\begin{tabular}{|l|c|c|c|c|}
\hline \multirow{2}{*}{\multicolumn{1}{|c|}{ Порода }} & \multicolumn{4}{c|}{ Прочностные показатели } \\
\cline { 2 - 5 } & $\sigma_{\text {сж1 }, \text { МПа }}$ & $\sigma_{\text {сж2, МПа }}$ & $p$ & $m$ \\
\hline Сильвинит & 29,0 & 115 & 0,67 & 0,35 \\
\hline Каменная соль & 33,0 & 65 & 0,41 & 0,30 \\
\hline Карналлит & 10,5 & 35 & 0,62 & 0,60 \\
\hline Ангидрит-доломитовая порода & 85,0 & 135 & 0,29 & 0,25 \\
\hline
\end{tabular}

На рис. 2 показан характер изменения теоретических кривых коэффициента формы в зависимости от соотношения размеров прямоугольных образцов исследуемых пород.

a)

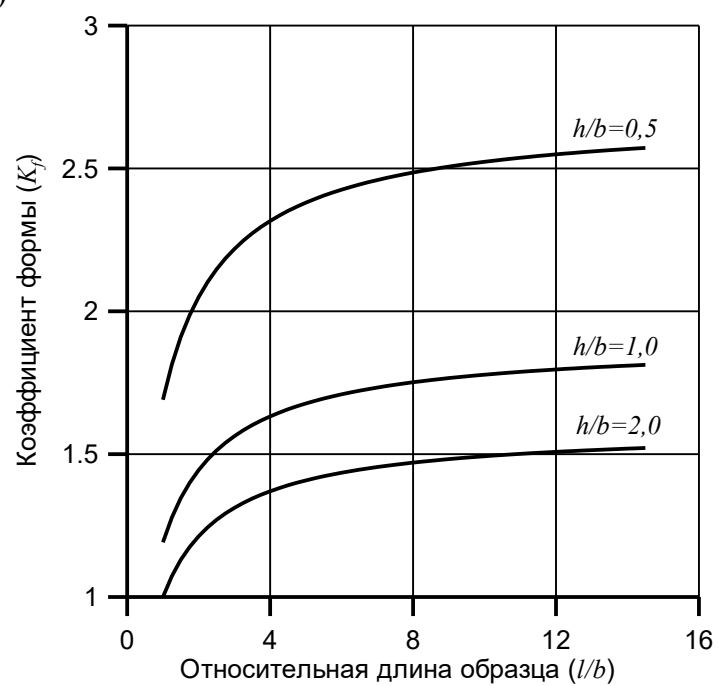

в)

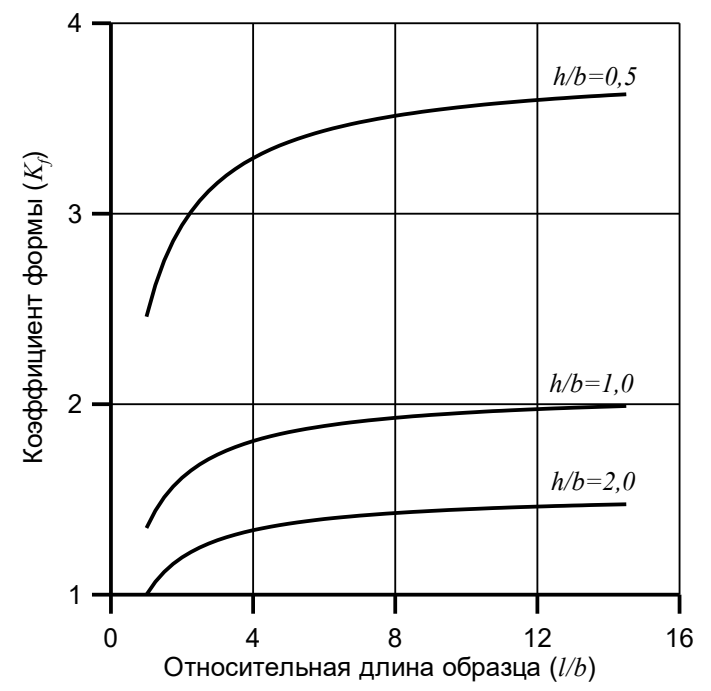

б)

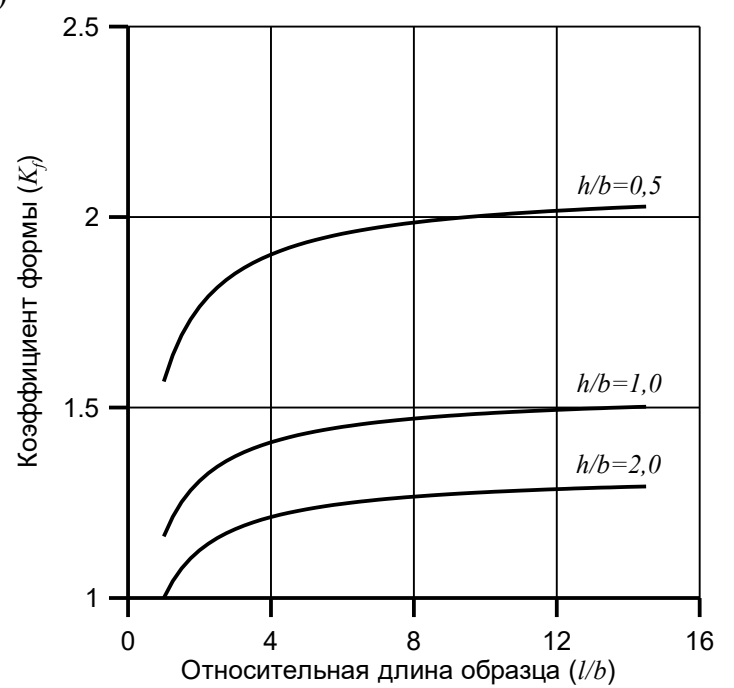

г)

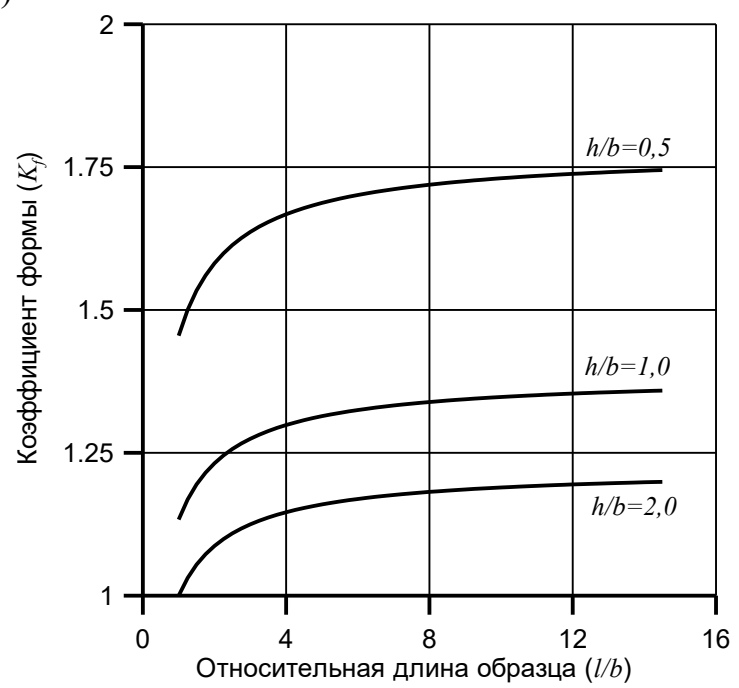

Рис. 2. Характер изменения теоретических кривых коэффициента формы в зависимости от соотношения размеров прямоугольных образцов пород Гремячинского месторождения калийных солей: a - сильвинит; б - каменная соль; в - карналлит; г - ангидрит-доломитовая порода 
Анализ результатов проведенных исследований позволил выдвинуть предположение (рис. 2), что более интенсивное увеличение коэффициента формы при изменении размеров образца имеет место для пород с пониженной прочностью и повышенной пластичностью.

Проведенные исследования направлены на уточнение методик расчета несущей способности междукамерных и предохранительных целиков различного назначения месторождений калийных солей.

Исследование выполнено при финансовой поддержке РФФИ и Пермского края в рамках научного проекта №19-45-590004 и программы ФНИ (проект № 0422-2019-0148-С-01).

\section{БИБЛИОГРАФИЧЕСКИЙ СПИСОК}

1. Ведмедев А.В. Коэффициент формы в расчётах подземных сооружений // Геотехническая механика: межведомств. сб. науч. тр. - Днепропетровск, 2004. - Вып. 51. - С. 250-257.

2. Паньков И.Л., Шубина С.В. Результаты экспериментальных исследований коэффициента формы образцов сильвинитовых пород Верхнекамского калийного месторождения // Актуальные проблемы повышения эффективности и безопасности эксплуатации горношахтного и нефтепромыслового оборудования. - 2018. - Т. 1. - С. 171-176.

3. Указания по защите рудников от затопления и охране подрабатываемых объектов на Верхнекамском месторождении калийно-магниевых солей: утв. ПАО «Уралкалий», ЗАО «Верхнекамская калийная компания», ООО «ЕвроХим-Усольский Калийный комбинат». - введ. в действие 30.03 .2017 в ред. 2014 г. - Пермь; Березники, 2014. - 130 с.

4. Паньков И.Л., Ударцев А.А. Экспериментальные исследования влияния длины прямоугольных образцов сильвинита на коэффициент формы // Горное эхо. - 2020. - № 3 (80). - С. 44-48. - DOI: 10.7242/echo.2020.3.8.

5. Паньков И.Л. О результатах разработки критерия прочности для условий истинного трехосного напряженного состояния горных пород // Горное эхо. - 2020. - № 1 (78). - С. 46-50. - DOI: 10.7242/echo.2020.1.10. 